\title{
TRANSFORMAÇÕES MORFOLÓGICAS E APROPRIAÇÃO URBANA: Uma análise configuracional da urbanidade de Blumenau/SC
}

\author{
Morphological transformations and urban appropriation: \\ A configurational analysis of the urbanity do Blumenau/SC
}

\author{
Carminatti, Karol Diego; \\ Doutorando do Programa de Pós-Graduação em Arquitetura e Urbanismo, Universidade Federal de Santa \\ Catarina - karolcarminatti.au@gmail.com \\ Reis, Almir Francisco \\ Professor do Programa de Pós-Graduação em Arquitetura e Urbanismo, Universidade Federal de Santa \\ Catarina-almir.reis@ufsc.com.br
}

\section{RESUMO}

Ainda recente nos estudos urbanos, a urbanidade surge como elemento fundamental para o entendimento das práticas sociais no espaço urbano. Conceituando o acolhimento que as cidades dão aos seus moradores e transeuntes, a urbanidade está relacionada com a morfologia dos espaços públicos e sua capacidade de atrair gente. Neste trabalho propomos investigar os efeitos da forma espacial e seus atributos como meio de possibilitar ou restringir as práticas sociais. Utilizando Blumenau, importante cidade catarinense, partimos de leituras teórico-metodológicas analisando o papel do traçado urbano e suas implicações no cotidiano. Através da teoria da Sintaxe Espacial e análises complementares de morfologia e apropriação urbana, pudemos identificar mudanças tanto de configuração como de uso. A dinâmica espacial no presente aponta mudanças significativas no centro histórico de Blumenau e o surgimento de um "novo centro", facultando uma migração da urbanidade da cidade.

Palavras chave: Urbanidade, traçado urbano, configuração espacial

Bloco temático: Morfologias urbanas

\begin{abstract}
Still recent in urban studies, urbanity emerges as a fundamental element for the understanding of social practices in urban space. Conceptualizing the reception that cities give their residents and passers-by, urbanity is related to the morphology of public spaces and their ability to attract people. In this work we propose to investigate the effects of the spatial form and its attributes as a means of enabling or restricting social practices. Using Blumenau, an important city in Santa Catarina, we start from theoretical-methodological readings analyzing the role of the urban layout and its implications in everyday life. Through spatial syntax theory and complementary analyses of morphology and urban appropriation, we were able to identify changes in both configuration and use. The spatial dynamics in the present point indicate significant changes in the historic center of Blumenau and the emergence of a "new center", allowing a migration of urbanity of the city.
\end{abstract}

Keywords: Urbanity, urban layout, spatial configuration

Topic: Urban morphologies 


\section{Introdução}

As relações entre forma urbana e apropriação social tem sido base para inúmeros debates no campo da arquitetura e do urbanismo. Reconhecemos logo de início, que não há outro lugar na cidade que possibilite tamanha interface como o espaço público, visto que é historicamente o lugar de todos, palco da vida coletiva e da democracia, resultado de sucessivas contribuições culturais e sociais em uma linha temporal. Além de abrigar o convívio humano mútuo também é o elemento que dá forma a cidade desenhando os seus espaços urbanos. O bom espaço público então, é aquele que produz lugares para permanecer, conversar ou apenas caminhar. Isto requer uma boa estruturação, não apenas na sua forma local, mas também na sua inserção com o todo da cidade.

Dentro da morfologia urbana estudar os potenciais de acolhimento dos lugares implica em reconhecer os atributos de urbanidade as quais a cidade está submetida. O desenho de um lugar público pode ser bastante acolhedor, mas também pode ser um grande limitador. Entendemos que os lugares que acolhem são aqueles que proporcionam a urbanidade, reunindo atributos de vitalidade. O contrário indicaria a inospitalidade do espaço urbano e sua limitação de produção e reprodução das práticas sociais.

A urbanidade trata da essência comum de uma cidade. O interesse em estuda-la surge de uma observação da realidade vivida onde experimentamos uma forte cultura de segregação e de limitação do convívio social, espaços e cidades nada convidativas e que pouco agregam para a produção e reprodução da vida urbana. Tal observação se torna ainda mais evidente se verificarmos com mais atenção os centros urbanos antigos. Neles o abandono de edifícios, o predomínio de atividades comerciais e a baixa apropriação urbana noturna são fáceis de serem notados. Em nossa pesquisa nos preocupamos em investigar os efeitos da configuração urbana sobre o cotidiano das pessoas, não apenas a nível local, mas buscando compreender tais efeitos em toda a cidade.

Como estudo de caso analisamos Blumenau, importante cidade do Estado de Santa Catarina. Com uma colonização alemã, Blumenau tem sua estrutura urbana consolidada em meio a um vale e a 165 anos vem transformando seu espaço urbano neste sítio físico bastante singular. Tendo no passado uma economia voltada ao setor têxtil, atualmente se transformou no mais importante polo tecnológico brasileiro, e em um destino turístico procurado por pessoas do mundo todo. O centro que historicamente foi o lugar de maior urbanidade, hoje perdeu grande parte desta característica. Seguindo a regra de muitas das cidades catarinenses, o centro original se tornou um centro financeiro, resumindo sua vida urbana aos horários estabelecidos pelos lugares de comércio e serviço.

A principal hipótese do trabalho é de que o crescimento urbano e as alterações na estrutura morfológica da cidade deram a Blumenau condições para a modificação da sua urbanidade, que até então se resumia ao centro histórico, deslocando-a para uma porção mais ao norte, fazendo surgir um "novo centro".

Objetivamos nesta pesquisa estudar o traçado urbano de Blumenau, sua configuração atual e o seu papel enquanto estruturador dos espaços públicos e propiciador de urbanidade. São objetivos específicos:

- Compreender as mudanças dos padrões de urbanidade sobre a estrutura total e local da cidade;

- Identificar atributos morfológicos da urbanidade.

Em nossa pesquisa, utilizamos como referencial teórico-metodológico leituras que abordam de forma direta a morfologia urbana e a apropriação social dos lugares públicos. As obras de Jane Jacobs (2011) e Kevin Lynch (2006) dão ao trabalho importantes conceitos sobre as dimensões físicas e sociais das cidades. Trazemos também, como principal elemento teórico, a metodologia da Sintaxe Espacial descrita por Bill Hillier e seus colaboradores (1984) da University College of London. Tal método se preocupa em correlacionar a forma urbana como um campo de possibilidades e restrições para as práticas sociais.

O trabalho inicia com uma breve leitura histórica da evolução do traçado urbano. Através da sintaxe espacial, são elucidadas possíveis mudanças nos modos de apropriação motivadas por modificações nas estruturas 
urbanas da cidade. Em um segundo momento caracterizamos o centro original no presente, ao mesmo passo que buscamos identificar o "novo centro" de Blumenau. Para isto são feitas análises morfológicas mais aprofundadas.

Os resultados encontrados corroboram com a hipótese lançada. Por mudanças na estrutura urbana, a urbanidade de Blumenau migrou fisicamente para a região mais ao norte da cidade fazendo surgir um lugar com possibilidades de centralidade a ponto de competir com o centro original. O centro histórico ainda é o lugar que reúne muita gente durante o dia, mas é no "novo centro" que a apropriação perdura para além dos horários comerciais, resultado da sua configuração espacial e da sua diversidade de usos.

\section{Referencial teórico}

Como discutimos previamente, o espaço púbico é o lugar da cidade que abriga todos, independentemente de credos, raças, posição ou classe social. Entretanto, um espaço tão democrático e comunitário também é constantemente confrontado por interesses econômicos e políticos sendo, em alguns casos, violado, negligenciado e abandonado. Este cenário nos fez rever o papel do espaço público e sua urbanidade no presente retomando sua importância nos estudos urbanos.

Nos dicionários, o termo urbanidade expressa uma conceituação de valores estabelecidos para o bom convívio em sociedade. Quando levamos este conceito ao campo da arquitetura e do urbanismo, percebemos que urbanidade diz respeito a interação entre pessoas que compartilham do mesmo espaço físico da cidade. O espaço público seria o principal agente de urbanidade, isto porque propicia o encontro entre semelhanças e diferenças criando um espaço integrador, pois segundo Peponis (1989, p.23) "se a sociedade enquadra as pessoas em diferentes classes, papéis e posições, o espaço urbano pode ser um dos meios de reintegração".

A apropriação se torna chave para um espaço urbano bem-sucedido pois um lugar que reúne uma diversidade de pessoas certamente possui qualidades. Neste sentido, em nossa pesquisa, buscamos estudar a apropriação urbana através de uma estrutura analítica, resgatando o trabalho desenvolvido por Gabriela Tenório (2012). Nele a autora defende que um espaço público de sucesso possui três fatores:

- Gente: um atributo aparentemente óbvio, mas que nos faz relembrar o quão importante é voltar o olhar para as pessoas. Um lugar pode ser considerado esteticamente interessante, mas se está vazio perde seu sentido de espaço público. Onde não há suporte à vida pública, o espaço público também não será bem-sucedido.

- Gente Variada: O espaço público bem-sucedido é aquele que também propicia uma copresença entre semelhantes e diferentes, moradores e estranhos, de classes e culturas distintas. Entretanto, não deverá haver a predominância de determinado grupo, pois os demais poderão se sentir intimidados no uso do espaço público.

- Gente, sempre: A garantia de pessoas passando por um lugar a toda hora e em todos os dias da semana torna-o um espaço com vida urbana. A vitalidade da cidade que é apenas garantida por horários comerciais acaba por configurar espaços públicos com "horas de validade".

Tenório (2012) também destaca a importância do espaço urbano como ambiente intermediador de trocas sociais, onde a urbanidade poderia se manifestar. Para a autora "(...) indivíduos compartilhando de um mesmo espaço físico podem interagir ou não. A questão principal, então, não recai na interação, mas no compartilhamento do mesmo espaço físico, sem o qual nenhuma interação se dá" (TENÓRIO, 2012, p.14). Vemos então que aspectos morfológicos estão presentes, porém são elementos que no passado já foram estudados, mas de outra maneira.

Na década de 60 Jane Jacobs e Kevin Lynch já buscavam compreender os efeitos da forma urbana na apropriação da cidade. Jacobs (2011) criticava a negação do espaço público materializado na cidade de Nova York através de paredes cegas, grandes áreas de estacionamentos e empreendimento privados. Por outro 
lado, a jornalista admirava os bons exemplos presentes na cidade. Reconhece sobre tudo que a apropriação do espaço público é a chave da sua segurança. Um espaço urbano mais frequentado e rodeado por um entorno com fachadas ativas contribuíam para uma efetiva vigilância não só entre moradores, mas também transeuntes. Jacobs observava ainda uma relação entre quadras curtas e apropriação urbana, elucidando que a vitalidade depende também das pequenas distâncias e facilidades do caminhar.

Kevin Lynch (2006) também se preocupou com a relação entre edifícios, lugares e pessoas. O autor trata a percepção do espaço como algo fundamental, indicando que vivemos a cidade do jeito que a percebemos. $\mathrm{E}$ neste caso a forma urbana tem papel importante, pois cria uma trama de ruas, praças e lugares que podem ser facilmente ou dificilmente percebidos, influenciando os nossos movimentos diários.

Jacobs e Lynch incorporam em seus trabalhos, mesmo que de modos distintos, a forma urbana. Fica evidente que a configuração dos espaços públicos já demonstrava relevância no estudo do comportamento humano, mas ainda sem muito aprofundamento. É importante ressaltar que o termo "urbanidade" não era explorado nesta época, mas as contribuições feitas por estes autores auxiliaram na formulação do conceito como qualidade da cidade.

Anos mais tarde, já na década de 80, a contribuição feita por Jane Jacobs e Kevin Lynch parece ganhar ainda mais força, indo de encontro com uma abordagem descritiva desenvolvida por Bill Hillier e Julien Hanson. Divulgada através do livro The Social Logic of Space (HILLIER E HANSON, 1984), a teoria elaborada pelos autores e denominada como Sintaxe Espacial, propôs um método de descrição da forma urbana, fundamentando-se na constatação de que há uma lógica social no espaço e uma lógica espacial na sociedade. Com base nesta teoria, nossa busca para analisar a urbanidade estaria condicionada a três fatores: A escala global, a escala local, e o campo de possibilidades de interações sociais dos espaços urbanos.

Para Hillier e Hanson (1984) o modo como as edificações estão distribuídas sobre um território são importantes, porém, por si próprios, não poderiam criar condições de urbanidade, pois a maneira como os lugares se posicionam com o contexto é mais importante. A configuração total de uma cidade condiciona esforços e situações às quais todos os edifícios e lugares são submetidos. A sua mudança implicaria no todo da cidade afetando também as localidades. E são justamente as localidades o segundo ponto de observação da Sintaxe Espacial.

As relações que edifícios estabelecem com a cidade ocorrem necessariamente através do espaço público e sua forma. Claramente as paredes cegas, os muros e os grandes empreendimentos privados, outrora já denunciados por Jane Jacobs, não constituem bons exemplos de interfaces entre edifício e cidade, entretanto se tornam elementos de análise da Sintaxe Espacial. Preocupados em estabelecer uma leitura morfológica também das estruturas urbanas locais, os autores insistem que espaços com maior convexidade são lugares melhor apropriados, pois de certa forma "envolvem" seus usuários.

Um espaço urbano bem conectado com a cidade e bem constituído a nível local podem provocar aquilo que Hillier e Hanson (1984) chamam de "comunidade virtual", terceiro fator de análise. Lugares públicos bem configurados tendem a criar um melhor campo de possibilidades de interação social. Peponis (1992) explica este conceito quando diz que "é claro, que as pessoas interagem, partilham ou trocam experiências entre si, ou mesmo que se notam mutuamente. A configuração determina apenas o notar potencial de outros, como o pano de fundo para uma sociedade ativa". (Peponis, 1992,p.82).

Estes três elementos consolidam uma configuração espacial, que por sua vez cria uma rede de caminhos possíveis que são frequentemente utilizados pelas pessoas nas suas práticas diárias. Este movimento cotidiano também é estudado pela teoria de Hillier e Hanson, (1984). Segundo os pesquisadores, o movimento exercido pelas pessoas ao se locomoverem no espaço urbano, tido como "movimento natural", é um efeito primário para ocorrer o surgimento de atividades que garantam vida neste espaço. $O$ espaço tem efeitos sobre os movimentos e sobre os atratores que se posicionam em áreas mais facilmente acessíveis aproveitando o fluxo estabelecido pelo movimento natural. 
A importância da configuração espacial - local e global - como componente que estrutura o movimento das pessoas retoma a abordagem feita por Kevin Lynch. As relações sociais que podem ser estabelecidas mediados por esta configuração, se serão efetivas ou não, tratadas por Hillier e Hanson como comunidade virtual, herdam características das condições de diversidade advogadas por Jane Jacobs. A urbanidade que buscamos reconhecer nesta pesquisa trata sumariamente destes conceitos. A vida na cidade, sua apropriação coletiva e sua capacidade de estabelecer interfaces sociais, se demonstram inerentes à forma do espaço urbano na medida que estabelecem meios para a civilidade entre indivíduos e suas práticas.

\section{Métodos de pesquisa e procedimentos}

A pesquisa aqui desenvolvida segue três passos metodológicos. São eles:

- Descrição da cidade, dos espaços públicos e do traçado urbano:

Nesta primeira etapa nos preocupamos em elaborar um breve panorama da evolução e transformação urbana de Blumenau, buscando reconhecer os espaços públicos da cidade. Bases cartográficas de 1864, 1955, 1974 e 2010 foram analisadas elucidando a construção do traçado urbano.

\section{- Análise sintática da configuração urbana atual:}

Na segunda etapa, analisamos a estrutura sintática de Blumenau, considerando o mapa de 2010. Leituras feitas sobre a estrutura total e local da cidade, foram realizadas. Estas leituras permitiram uma descrição precisa das condições do tecido urbano atual da cidade, bem como a explicação no movimento das condições de urbanidade.

\section{- Análise dos lugares criados:}

Na terceira etapa da investigação, analisamos com maior profundidade o centro da cidade e o "novo centro". Foram consideradas observações sobre a localização da fração analisada em relação as variáveis globais, a leitura dos atributos formais locais, a leitura das atividades presentes no uso do solo e a leitura da copresença.

\section{Construção e transformação do traçado urbano de Blumenau}

Com uma formação inicial derivada dos lotes estreitos e compridos definidos pelo traçado colonial, Blumenau se expandiu lentamente entre os morros e os rios. As indústrias tiveram papel importante na configuração espacial contribuindo para a implantação de infraestrutura, moradia e sistemas de movimento. Nos últimos 70 anos o crescimento da cidade se intensificou e juntamente com ele ocorreram mudanças significativas no traçado implicando em novos modos de apropriação socio-espacial. Primeiramente se concentrando na área central da cidade e hoje se espalhando por todo o território blumenauense, em especial a região norte, o traçado claramente apresenta heranças culturais herdadas do seu processo de ocupação. Destacam-se neste processo:

- Um núcleo que articulou a formação da cidade e propiciou a ocupação urbana expansiva;

- As preexistências naturais como limitadores da ocupação;

- Uma estrutura fundiária essencialmente advinda de lotes coloniais e posteriormente reconfigurada com o parcelamento gradativo dos lotes originais;

- Um advento industrial que, consolidou o centro e impulsionou o crescimento da cidade modificando e expandindo o traçado urbano;

- Um sistema de movimentos definido em três níveis: Um primeiro momento que se articulou por vias aquáticas e ordenou o território colonial demarcando-o em ocupações lineares, posteriormente por uma linha férrea que facilitou o translado de mercadorias e, atualmente com a desativação destes dois, 
se consolidou através de uma rede articulada por ruas e rodovias resultantes de uma política rodoviarista;

- A consolidação de diversas e áreas e a expansão do traçado urbano para região norte da cidade.

O espaço urbano de Blumenau, portanto, foi um resultado de processos históricos com fortes influências culturais. O traçado da cidade se organizou de tal maneira que permitiu uma estrutura dispersa (fig.01) organizando também o espaço público, reconhecendo nas ruas o seu principal valor.
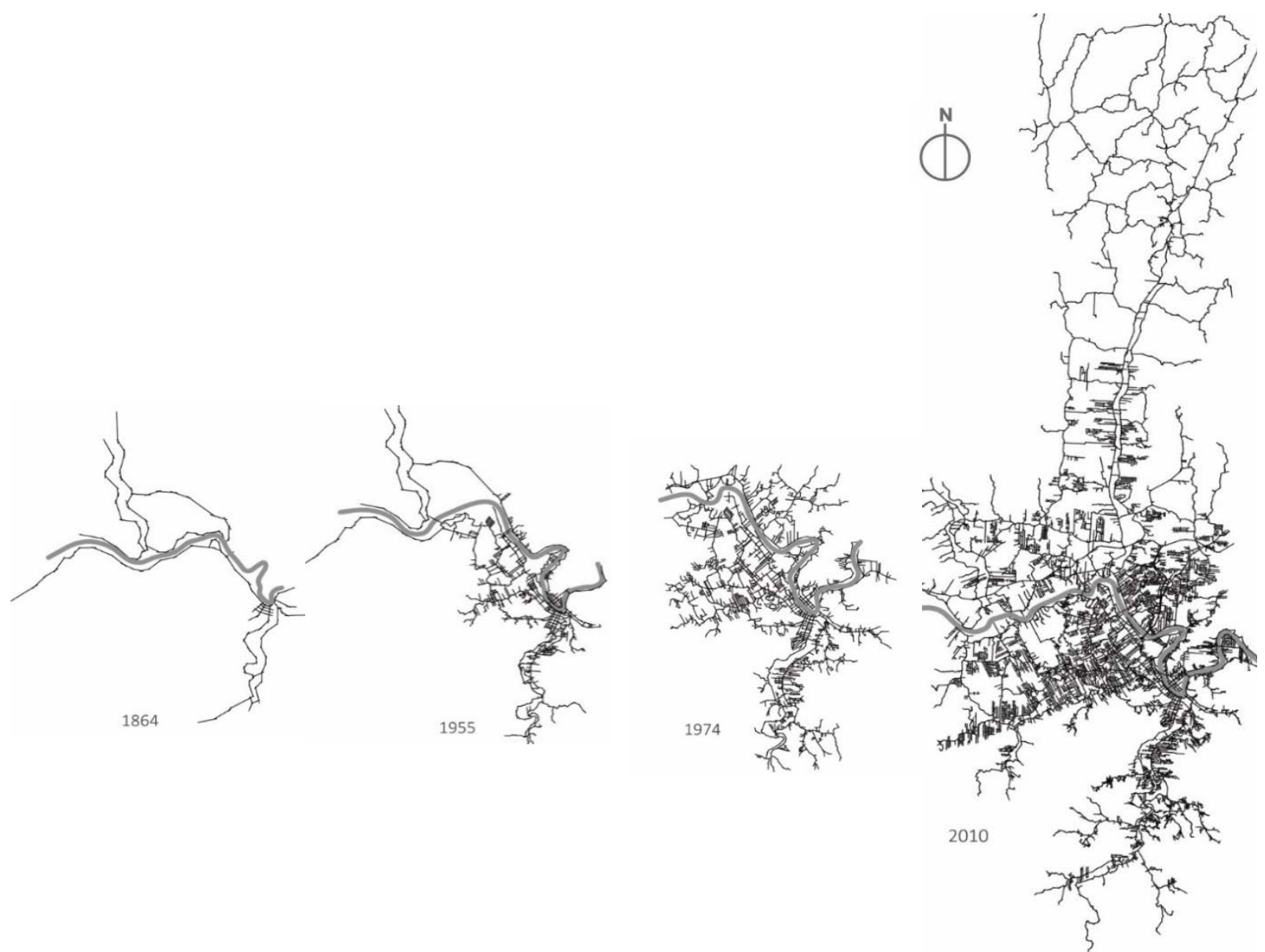

Fig. 01 Crescimento e expansão do traçado urbano de Blumenau. Fonte: Elaboração própria com base em mapas históricos da cidade.

\section{A estrutura sintática de Blumenau}

Procurando entender a forma urbana como campo de possibilidade para a interação social, analisamos o traçado urbano de Blumenau enquanto estruturador da rede de espaços públicos, utilizando a teoria e o método da Sintaxe Espacial, tratando-o como um sistema de barreiras e permeabilidades, buscando identificar condições de urbanidade inerentes a sua configuração.

Na teoria da Sintaxe Espacial, Hillier e Hanson (1984) identificam medidas que podem ser mensuradas e que tratam da relação entre os espaços urbanos públicos. Utilizamos a principal medida que, a nosso ver, relaciona muito bem os aspectos configuracionais com a busca por aferir graus de urbanidade: a medida de integração. Esta medida reduz a cidade a um sistema, analisando relações entre cada elemento que a compõe. Resumidamente, todo o espaço público, neste caso voltado ao pedestre, é representado por uma sequência de linhas que se conectam. Desta forma, ruas, praças, parques e espaços abertos públicos são tomados como componentes que integram o sistema, analisando o quão próximo ou distante cada um destes elementos está 
em relação a outro e a outros. Uma linha mais próxima em relação a todas as outras, será considerada integrada pois, espacialmente se torna mais facilmente acessível. O contrário disso indicaria uma linha com grau de segregação, ou seja, pouco acessível.

Sobre o mapa sintático de 2010 (fig.02) é possível observar linhas derivadas de um período de grande expansão do traçado urbano. O conjunto de linhas mais integradas no todo aparece fora do centro original e se estabelece em uma porção territorial mais ao norte. Abrangendo áreas importantes que englobam o campus da Universidade Regional de Blumenau (FURB), o Parque Vila Germânica e a região mais adensada da cidade, este lugar configura um núcleo de integração global. Significa reconhecer que, se observada a cidade como um todo, é lugar mais fácil de se acessar e com um potencial maior para movimentos intraurbanos. Os espaços mais segregados estão situados na região norte e no extremo sul da cidade. Percebe-se um grau de descontinuidade tanto do território quanto do processo de ocupação urbana destas áreas. Frações urbanas pouco diversificadas e que não geram espaços públicos bem constituídos compõem a região norte que, por sua vez, estando em uma localização favorável em relação a BR-470 e a SC-108, detém grandes áreas com usos industriais.

Observando o mapa de integração local buscamos compreender os espaços que configuram o entorno imediato de cada linha analisada. Tal observação revela os centros secundários que progressivamente vão surgindo no tecido urbano e estruturando localmente os diversos bairros da cidade. Neste caso, em Blumenau, as áreas com maior integração local coincidem com a integração global, evidenciando um núcleo de grande potencial de urbanidade. Chamamos este núcleo integrador de "centro sintático".

Para que uma determinada área possua uma estrutura urbana apropriada e diversificada diariamente, atraindo consumidores e garantindo a vitalidade, Penn et al (1998) e Hillier (2009) argumentam que determinada região necessitaria de uma sobreposição da Integração local e global. Se houvesse apenas Integração local, o lugar se resumiria em equipamentos de pequeno porte que atendem à vizinhança. Se houver apenas Integração Global é característico que a área se torne um lugar de passagem com uma grande dependência do transporte individual. Ambos os casos puderam ser aferidos na estrutura urbana de Blumenau.

As condições de integração estão inerentes à capacidade de um lugar em possuir vida e apropriação. Por mais que não tenha hoje uma vitalidade tão expressiva quando o centro original, as características sintáticas presentes na região universitária da cidade evidenciam uma configuração espacial mais propícia para o movimento natural e ocorrência de encontros aleatórios, estando propícia também para efetivação da urbanidade. 


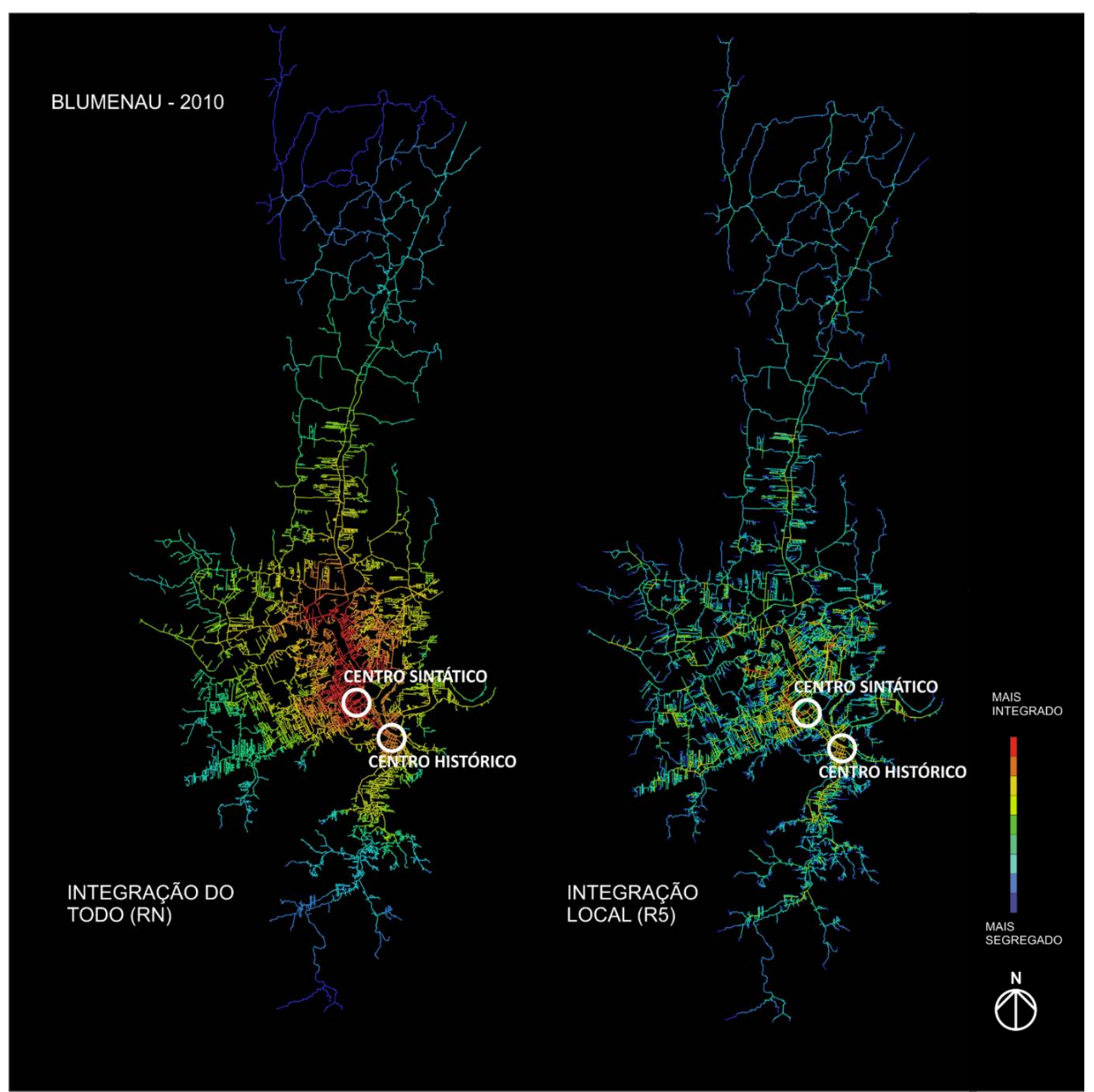

Fig. 02 Mapas axiais de integração local e do todo utilizando a base cartográfica de 2010 evidenciando os lugares prováveis de urbanidade. Fonte: Elaboração própria a partir de mapas históricos da cidade.

\section{Do centro histórico ao centro sintático}

O sistema de potencial copresença de pessoas, que é organizado pela forma dos dois centros, são aqui completados com análises locais mais específicas (fig.03) de categorias derivadas das atividades, usos e agentes que atuam no espaço urbano, investigando elementos de conteúdo formal e social presentes nas duas áreas. Consideramos importante observar:

- A Localização da fração analisada em relação as variáveis globais, para compreender a influência dos atributos de integração sobre as duas áreas;

- A Leitura dos atributos formais locais, para analisar a morfologia e a constituição dos lugares e identificar espacialidades que propiciem interfaces sociais; 
- A Leitura das atividades presentes no uso do solo, para reconhecer lugares de atratividade e que auxiliem na apropriação dos espaços públicos;

- A Leitura da copresença, para aferir in loco a assiduidade das pessoas no espaço urbano.

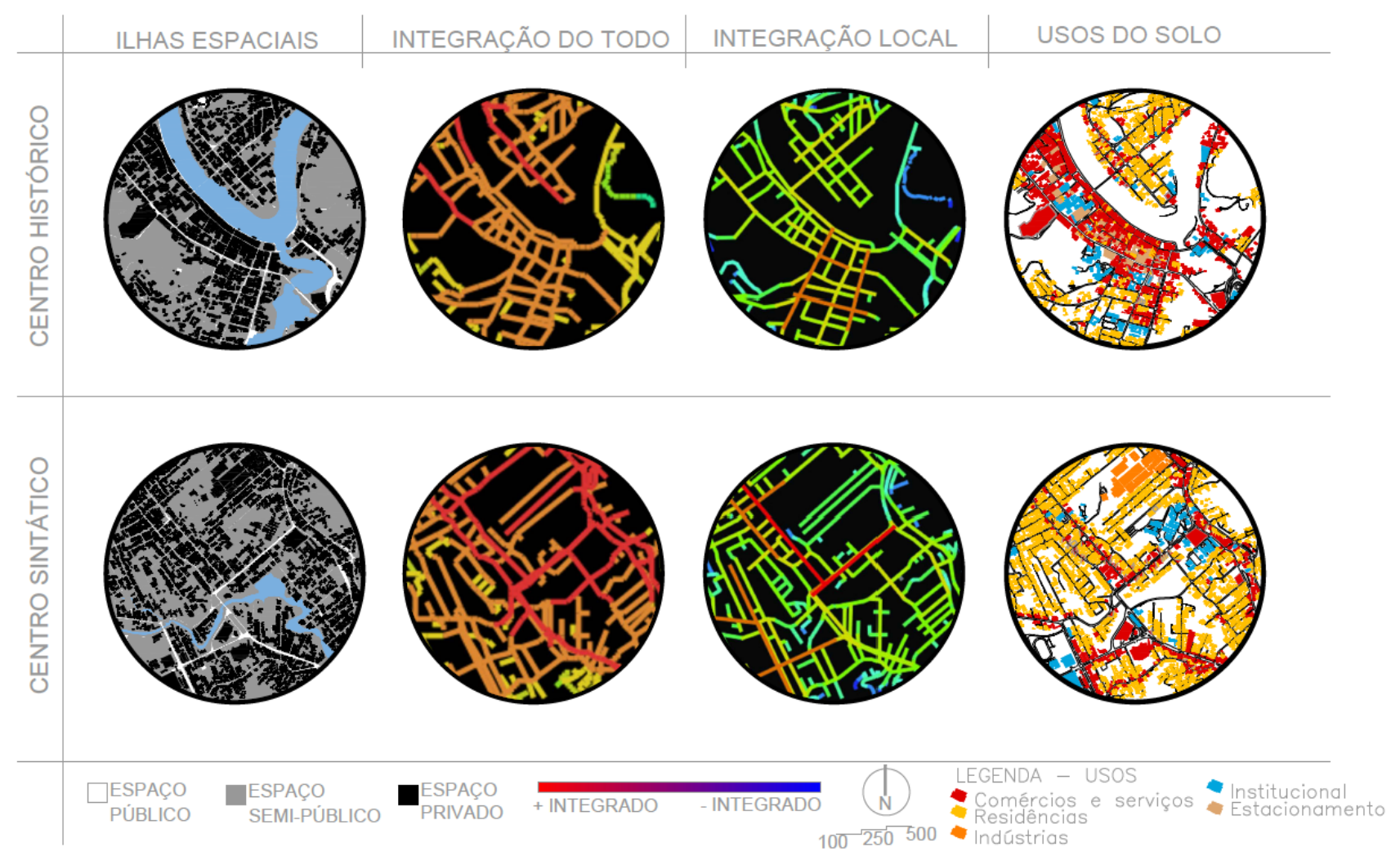

Fig. 03 Mapas de análise local considerando configuração, morfologia e usos do solo. Fonte: Elaboração própria com base em mapas cartográficos de 2010

\subsection{A Localização da fração analisada em relação as variáveis globais}

O centro histórico apresenta uma baixa integração axial localmente e no todo. Os lugares sintaticamente mais integrados, se confirmam na região universitária. Sobrepondo integrações locais e totais, é um lugar com vida urbana estruturada em atividades (comércios, serviços, moradia) que atendem um caráter local, e ao mesmo tempo, possibilita a atração e interação de pessoas de outras partes da cidade.

\subsection{A Leitura dos atributos formais locais}

Com um traçado retangular, formas bem constituídas e edificações que criam uma borda alinhada, percebe-se que a sequência morfológica de espaços privados frente aos espaços públicos é mais clara na região do centro histórico. Por possuir tal característica, onde os cheios se sobressaem aos vazios, tende a promover uma apropriação mais intensa com uma maior concentração de fluxos. O contrário se percebe no centro sintático, onde lugares em que os vazios são mais numerosos, e edificações que resultam espalhadas, acabam por não constituir uma unidade clara. Nestas porções uma baixa relação espacial entre o público/privado se estabelece, e a rua, em alguns momentos, quase que inteiramente se destina para a circulação de veículos.

\subsection{A Leitura das atividades presentes no uso do solo}

No centro histórico se concentra um variado comércio varejista, juntamente com uma grande oferta de serviços e alguns usos públicos e institucionais, fazendo com que a apropriação dos lugares fique concentrada nos horários comerciais. Usos habitacionais são quase inexistentes e aparecem no bairro ponta aguda, na margem esquerda do rio, oposto ao centro histórico. Na região sintática, reconhecemos uma diversidade bastante grande de usos, onde atividades comercias e de serviços se mesclam meio a numerosas áreas residenciais. 
Percebe-se que a grande quantidade de moradias presente nesta porção tem relação direta com a localização da Universidade Regional de Blumenau.

\subsection{A Leitura da copresença}

Considerando as viáveis descritas por TENÓRIO (2012), buscamos correlacionar os atributos até agora vistos com a apropriação dos lugares públicos. Nesta análise consideramos perceber indicadores relacionados à:

- "Gente":

O centro histórico se insere nesta característica concentrando uma elevada apropriação urbana, garantida pelo alto índice de atividades comerciais e de serviços, onde se estabelece uma relação bastante explícita entre interiores de usos comercias e o exterior público, propondo inúmeras possibilidades de interações sociais. Uma ocupação bem mais diluída ocorre no centro sintático, onde não percebemos a quantidade de gente como no centro histórico. Em parte do tempo o movimento da rua é garantido pelos carros, que aumenta consideravelmente em horários de pico. Os pedestres se apropriam das calçadas em maior número quando as atividades institucionais universitárias estão prestes a iniciar ou finalizar.

- "Gente Variada":

Em ambos os centros é notada uma diversificação dos padrões de arranjos sociais. Na porção histórica, o grande número de gente diferente se dá pelo significado do lugar. Sendo praticamente um centro de finanças e de atividades comerciais de Blumenau, pessoas de todas as partes da cidade, e de outras cidades ali se encontram. Na porção sintática, a diversidade de gente também é bastante percebida, principalmente próxima à região universitária. Com um importante papel a nível regional, a FURB atrai estudantes dos mais diversos lugares do país e do mundo, garantindo um conteúdo social tão diverso quanto aquele que percebemos no centro histórico.

- "Gente sempre":

Uma grande apropriação urbana ocorre na porção histórica da cidade, com muita gente e gente diferente (fig.04). Porém, após as 18:00 horas um esvaziamento toma conta do centro (fig.05). O espaço que detém a maior vida urbana da cidade durante o dia, à noite se transforma em um lugar inóspito. Os finais de semana seguem com este cenário sendo que em alguns dias o centro histórico recebe atividades culturais como tentativa de reanima-lo. Reconhecemos um sinal claro da falta de estruturas sociais em consequência da ausência de usos residenciais. Diferente da porção central de Blumenau, o centro sintático consegue estruturar uma coopresença para fora dos horários comerciais, durante e no final da semana. Mesmo sem a quantidade de pessoas do centro histórico, percebe-se esse fenômeno por meio do "mix" de atividades que ali se estabelecem, onde interfaces sociais são mais percebidas nos momentos noturnos (fig.06 e 07). 


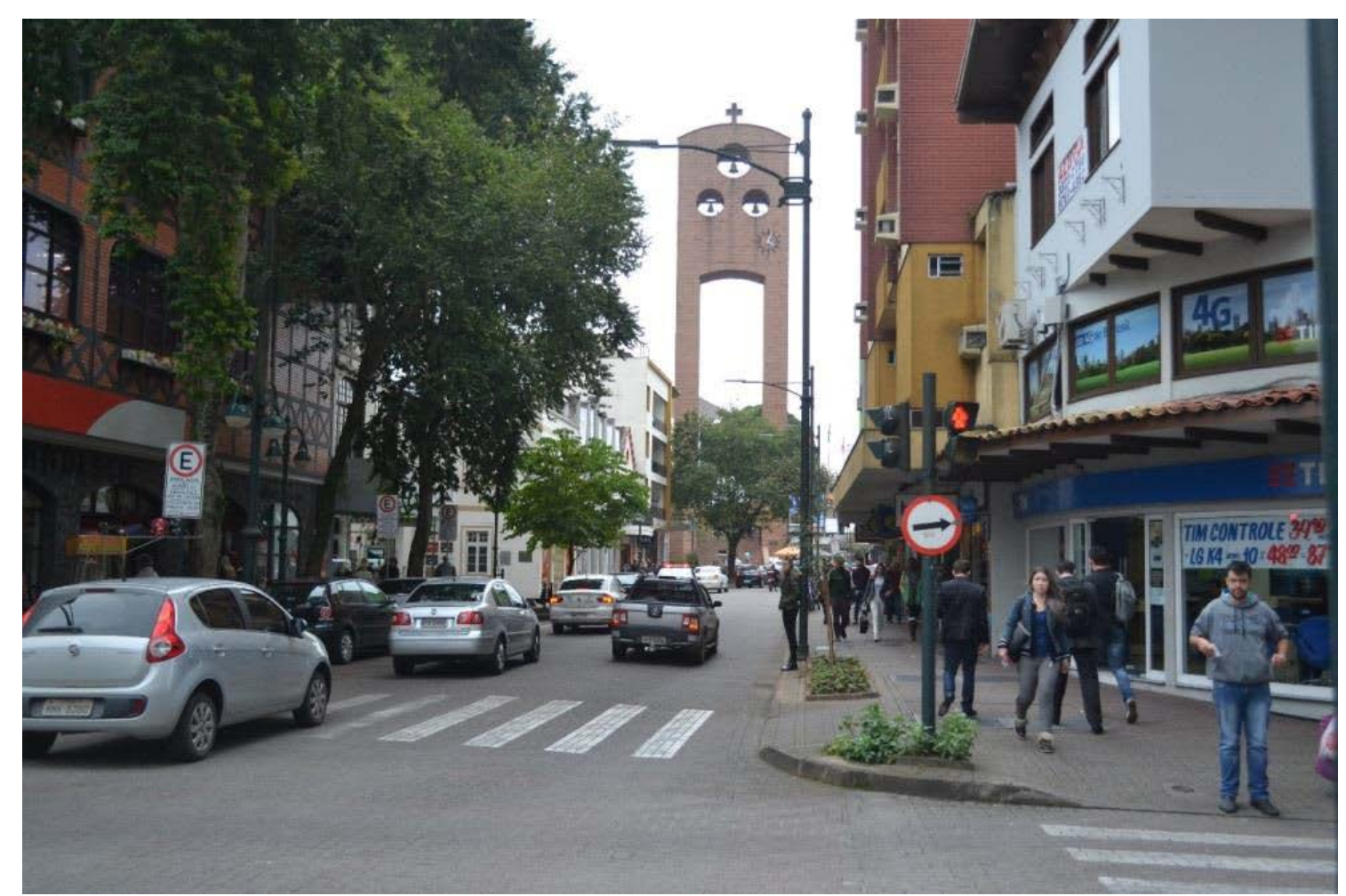

Fig. 04 Centro Histórico de Blumenau durante a semana, de dia. Fonte: Acervo do autor

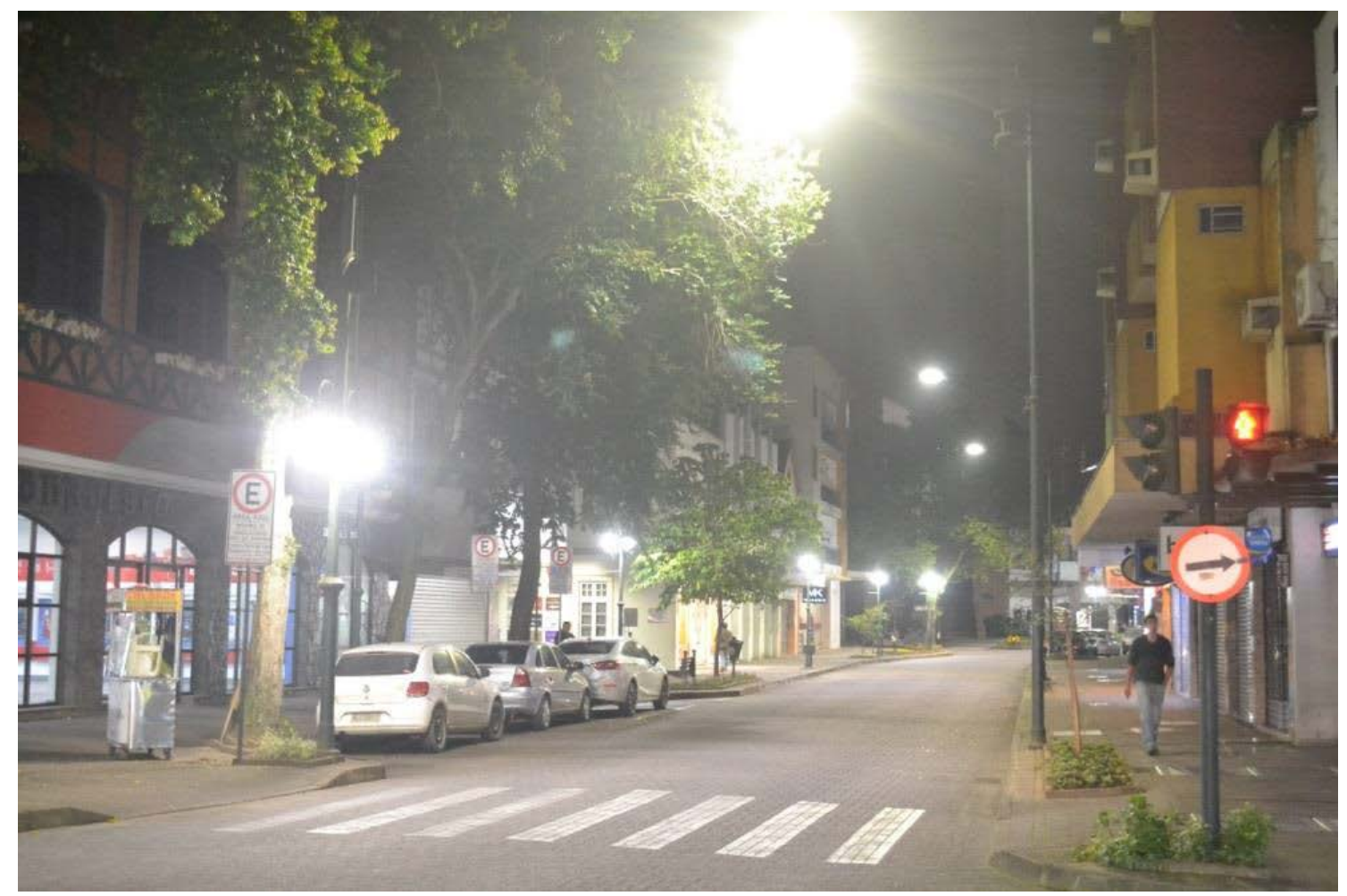

Fig. 05 Centro Histórico de Blumenau durante a semana, à noite. Fonte: Acervo do autor 


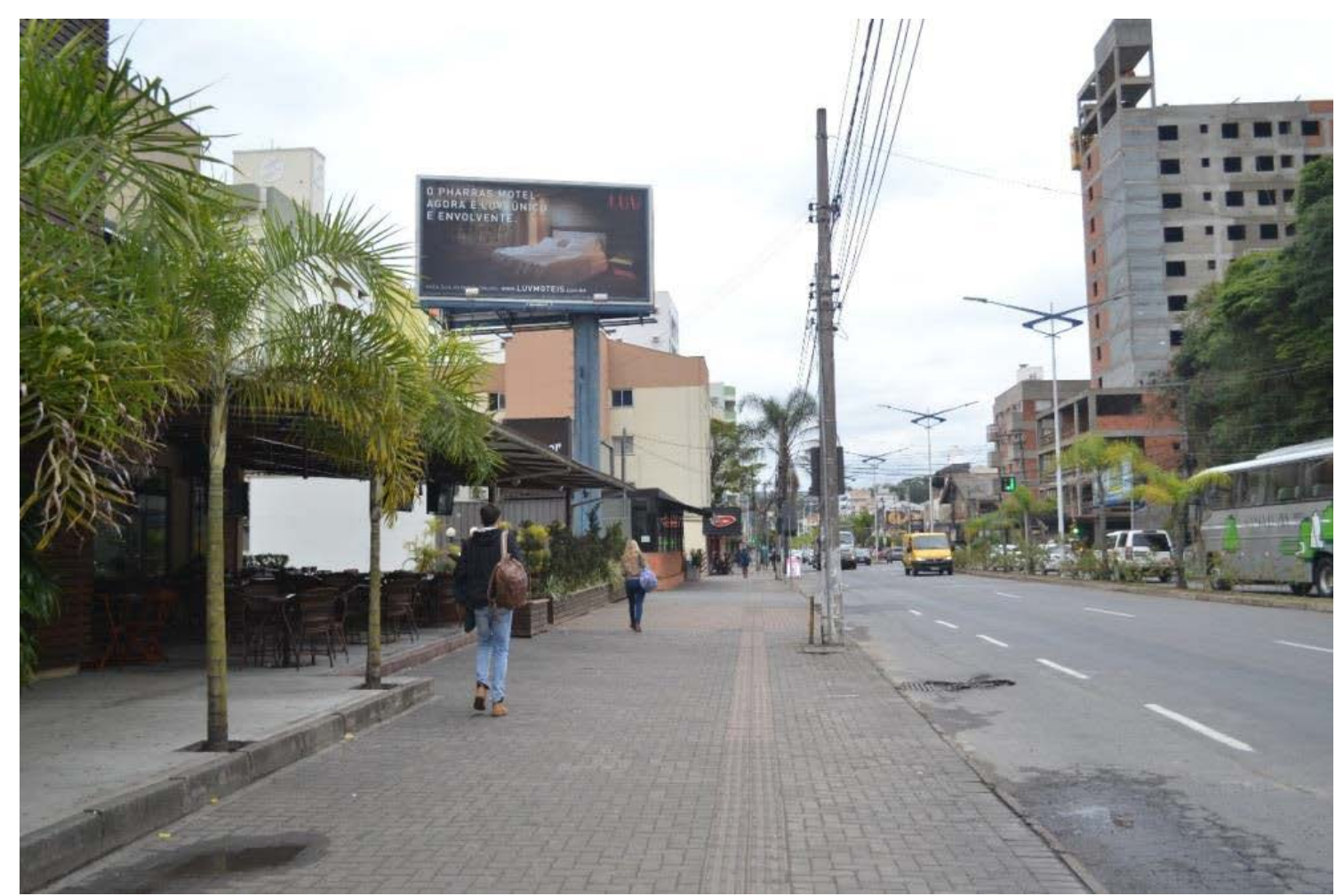

Fig. 06 Centro Sintático de Blumenau durante a semana, de dia. Fonte: Acervo do autor

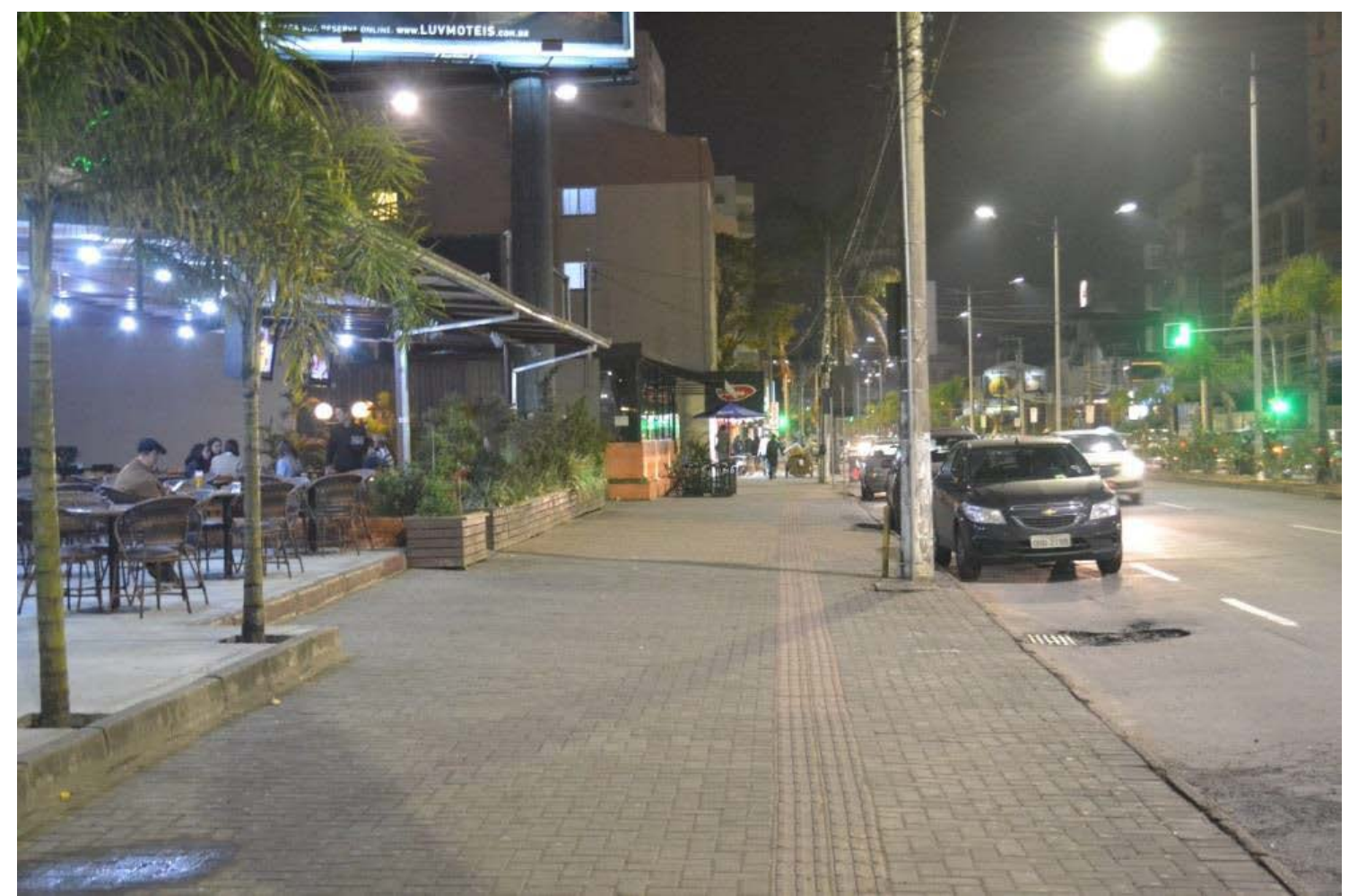

Fig. 07 Centro Sintático de Blumenau durante a semana, de dia. Fonte: Acervo do autor 


\section{Considerações finais}

Como elemento fundamental, o traçado urbano de Blumenau explicita mudanças significativas na organização e uso dos espaços públicos da cidade, e através da sintaxe espacial pudemos comparar suas possibilidades de interfaces sociais. A Inferência mais recente sobre a estrutura sintática da cidade demonstrou o núcleo integrador já deslocado. Facultando uma migração dos padrões de copresença do centro histórico, o centro sintático se configura na região universitária e seus arredores. A região norte de Blumenau aparece como o lugar mais segregado.

Os baixos valores de integração do todo que se concentram no centro original possuem uma correlação direta com a delimitação do seu sitio físico natural. O rio Itajai-Açú e os morros restringem as possibilidades de conexão com outros setores da cidade, enquanto que na região universitária o traçado urbano se estabeleceu através de um alto grau de conectividade com o seu contexto. A integração local demonstra maiores potencialidades nesta região. Já no centro histórico, sintaticamente, não há uma configuração com alta integração a nível local.

Ao final da pesquisa, o centro sintático se revelou como o novo "coração" da cidade, onde as possiblidades de interfaces entre os diversos agentes da vida urbana podem se consolidar de melhor forma. Mesmo ainda não sendo tão clara esta vocação, as análises locais identificaram a potencialidade em atrair gente. Fica evidente que grande parte desta potencialidade se dá pelo fato do centro sintático ser um lugar bastante conectado e muito diversificado onde atividades cotidianas ocorrem involuntariamente. Bares e restaurantes se apropriam do espaço público e abrem possibilidades para o encontro e a permanência. A presença de inúmeros edifícios residenciais tanto quanto as diversas atividades comerciais criam uma copresença duradoura que se fortalece com as atividades da Fundação Universidade Regional de Blumenau, elemento responsável por atrair grande quantidade de gente.

A urbanidade, no caso de Blumenau, resultou então como uma qualidade intrínseca da configuração urbana. A forma da cidade, suas tipologias edificadas e os lugares abertos disponíveis para as pessoas condicionaram diretamente o modo como a cidade é vivida e apropriada no cotidiano, e demonstram de forma clara como mudanças na estrutura urbana influenciam dinâmicas sociais.

\section{BIBLIOGRAFÍA}

HILLIER, B. y HANSON, J. (1984). The Social Logic of Space. Cambridge: Cambridge University Press.

HILLIER, B. (2009). Spatial sustainability in cities: Organic patterns and sustainable forms. Seventh International Space Syntax Symposium, Stockholm: Royal Institute of Technology, 8-11 junho (meio digital)

JACOBS, J. (2011). Morte e vida de grandes cidades. São Paulo: Martins Fontes.

LYNCH, K. (2006). A imagem da cidade. São Paulo: Martins Fontes.

PENN, A. et al. (1998). Configurational modelling of urban movement networks. Revista Environment and Planning B: Planning and Design (Reino Unido), 25, 59-84.

PEPONIS, J. (1989). Espaço, Cultura e Desenho Urbano no Modernismo Tardio e Além Dele. Revista Ekistics (Austrália), 56, 93-108 - (1992) Espaço, Cultura e Desenho Urbano. Revista AU, 41, 78-83.

TENÓRIO, G. S. (2012). Ao desocupado em cima da ponte. Brasília, arquitetura e vida pública. Brasília: UNB 